\title{
Mesenchymal stem cells and extracellular vesicles in therapy against kidney diseases
}

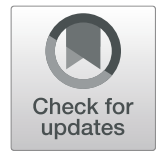

Yuling Huang and Lina Yang*

\begin{abstract}
Kidney diseases pose a threat to human health due to their rising incidence and fatality rate. In preclinical and clinical studies, it has been acknowledged that mesenchymal stem cells (MSCS) are effective and safe when used to treat kidney diseases. MSCs play their role mainly by secreting trophic factors and delivering extracellular vesicles (EVs). The genetic materials and proteins contained in the MSC-derived EVs (MSC-EVs), as an important means of cellular communication, have become a research focus for targeted therapy of kidney diseases. At present, MSC-EVs have shown evident therapeutic effects on acute kidney injury (AKI), chronic kidney disease (CKD), diabetic nephropathy (DN), and atherosclerotic renovascular disease (ARVD); however, their roles in the transplanted kidney remain controversial. This review summarises the mechanisms by which MSC-EVs treat these diseases in animal models and proposes certain problems, expecting to facilitate corresponding future clinical practice.
\end{abstract}

Keywords: Kidney diseases, Mesenchymal stem cells, Extracellular vesicles

\section{Introduction}

Kidney diseases have become an important global health issue as their incidence and fatality rate increase [1]. Common kidney diseases include acute kidney injury (AKI), chronic kidney disease (CKD), diabetic nephropathy (DN), lupus nephritis, and hypertensive nephropathy, induced by various causes. The main therapeutic methods against these kidney diseases include drug therapy, dialysis, and kidney transplantation [2,3]; however, new therapies emerge due to the limitations of drug therapy, inconvenience of dialysis, and shortage of donors for kidney transplantation [4]. In recent years, stem cells, as a new regenerative therapy, have been used to treat numerous diseases, including kidney diseases [5]. Therefore, MSCs have become a new means of treating kidney diseases. Compared with MSCs, treating kidney diseases with MSC-derived extracellular vesicles (MSCEVs) is characterised by advantages such as lower immunogenicity and tumorigenicity [6]; however, the

\footnotetext{
* Correspondence: yanglina1984@163.com

Departments of Geriatrics, The First Affiliated Hospital of China Medical

University, 155th Nanjing North Street, Shenyang 110001, Liaoning, China
}

pathway and mechanism of action of MSC-EVs in treating kidney diseases have not been elucidated, and the clinical use of MSC-EVs is still being explored. Considering this, in this review, we summarise the status of research involving MSC-EVs in the treatment of kidney diseases.

\section{MSC-EVs \\ Biological characteristics of MSCs}

Stem cells can be divided into two categories: embryonic and adult stem cells, according to their stage of development. Adult stem cells refer to the undifferentiated cells in differentiated tissues and are present in various tissues and organs of a body. MSCs, as a type of self-renewing multipotent adult stem cell, can be differentiated into diverse types of cells. MSCs can be isolated from numerous tissues such as bone marrow-derived MSCs (BMMSCs) [7], adipose-derived MSCs (ADMSCs) [8], human umbilical cord-derived MSCs (huMSCs) [9], human placenta-derived MSCs [10], and those from the dental pulp, skin, blood, and urine [5, 11]. In the existing research, BMMSCs, ADMSCs, and huMSCs are mainly 
used. Researches have shown that MSCs locate to injured areas via direct interaction and the paracrine effect $[12,13]$, while being less dependent on the differentiation function [14]. Through marking, it is found that, after being injected into the body, MSCs can be specifically located in the injured zones of the kidney [15-17]. The molecular mechanisms of MSC homing are based on a multistep model, including initial tethering by selectins, activation by cytokines, arrest by integrins, diapedesis or transmigration, and migration toward chemokines [18]. It should be noted that chemokines and their receptors are recognised as important mediators of MSC homing; however, low expression levels of homing molecules limit the efficacy of MSC therapy [19]. de Witte et al. and Schrepfer et al. have described that the main problem after MSC administration is that they do no target the target tissue, limiting their therapeutic effect $[20,21]$. Then, target administration, magnetic guidance, genetic modification, and cell surface engineering, among others, are studied to facilitate MSC homing [18]. MSCs are administered to target tissues mainly by systemic delivery and local delivery, the former including intra-arterial and intra-venous and the latter including topical, intra-muscular, direct tissue injection, and catheter-based direct implantation. However, there is no consensus on the optimal method for MSC infusion [12]. Also, MSCs can act on peripheral cells by secreting trophic factors such as growth factors, chemokines, and cytokines or deliver subcellular structures and even mitochondria by forming tunnelling nanotubes, secreting extracellular vesicles (EVs) and fusing with cells [22]. Therein, the synthesis and release of EVs that contain proteins, messenger ribose nucleic acid (mRNA), and micro-ribose nucleic acid (miRNA) through paracrine have become the focus of current research. In short, MSCs/MSC-EVs can function in different ways, as shown in Fig. 1.

\section{Biological characteristics of EVs}

EVs, a type of nanoscale vesicles encapsulated by cytomembranes, can be divided into exosomes (Exos), microvesicles (MVs), and apoptotic bodies (Fig. 1), whose diameters are $30-150 \mathrm{~nm}, 200-1000 \mathrm{~nm}$, and $800-5000 \mathrm{~nm}$, respectively [23]. EVs, as an important means of intercellular communication, are widely present in the body fluids, including blood, urine, and amniotic fluid. EVs enter endosomes to form multivesicular bodies (MVBs) by way of budding, then MVBs are combined with cytomembranes to release EVs [24]. EVs contain DNA, RNA, proteins, and lipid, and the substances contained in EVs are specifically determined by metrocytes [25]. This lays the foundation for the use of EVs as a diagnostic marker of disease. As a non-invasive diagnostic marker, EVs have attracted much attention.

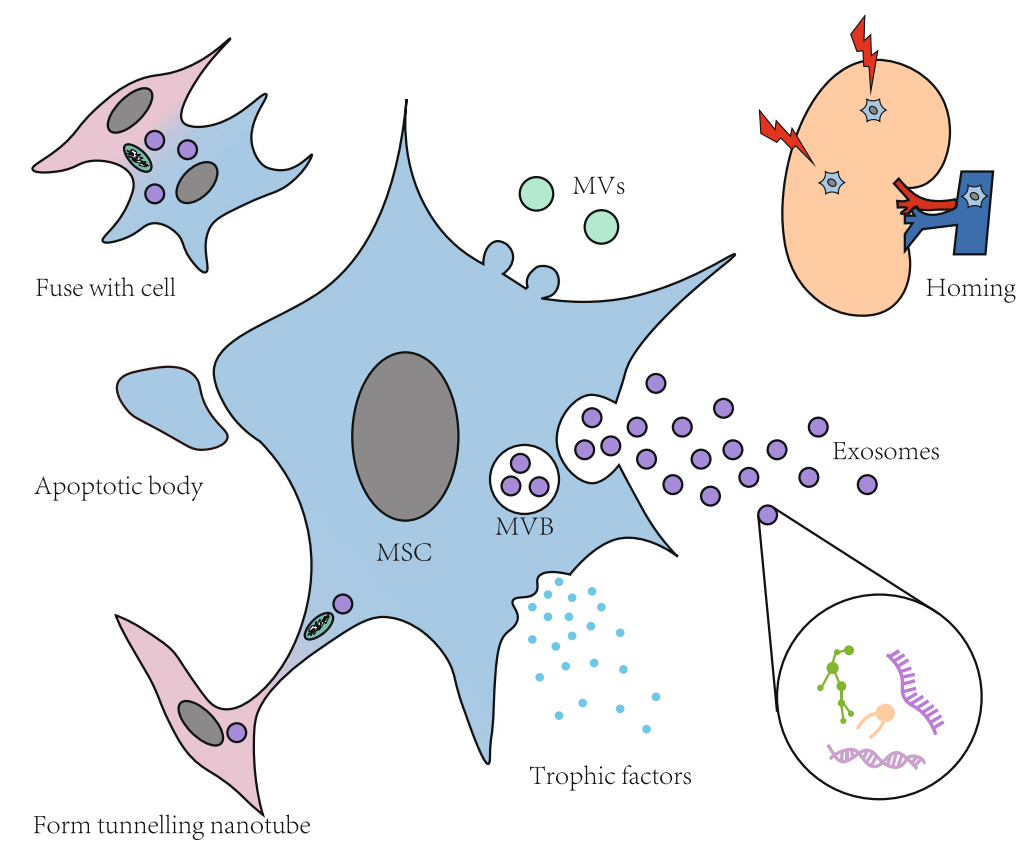

Fig. 1 The function of MSCS/MSC-EVs. MSCs can be specifically located in the injured zones of the kidney. Then, MSCs act on peripheral cells by secreting trophic factors such as growth factors, chemokines, and cytokines, or deliver subcellular structures and even mitochondria by forming tunnelling nanotubes, secreting EVs, and fusing with cells. EVs enter endosomes to form MVBs by way of budding, then MVBs are combined with cytomembranes to release EVs. EVs can be divided into exosomes, MVs, and apoptotic bodies. EVs, specially Exos, contain DNA, RNA, proteins, and lipid. MSCs, mesenchymal stem cells; EVs, extracellular vesicles; MVBs, multivesicular bodies; MVs, microvesicles 
For example, miRNAs of urinary Exos reliably reflect the progression of AKI [26]. EVs are used to characterise the rejection in allogeneic heart transplantation [27]. MSC-EVs can delay the progression of kidney diseases through mechanisms of anti-apoptosis, anti-inflammation, anti-fibrosis, antioxidation, etc. Other research also found that EVs derived from other sources can also improve renal function, including renal tubular cells [28, 29], glomerular MSCs [30], MSCs isolated from testis [31], and even urine [32]. These EVs ushered in a new way of treating kidney diseases.

Moreover, EVs can play a wider spectrum of roles under bioengineering design and control. EVs can carry many types of drugs via pre- and post-release modification [33] and play their therapeutic role by loading substances thereon and subsequent targeting [34], such as micro-molecules, proteins, and nucleic acids [35]. EVs have become a research focus as a drug carrier for various diseases, such as carrying antineoplastic [36] and anti-inflammatory [37] drugs. The specificity of uptake of EVs is highly dependent on the surface of EVs and acceptor cells, including integrins, proteoglycans, lectins, glycolipid, and others, which can aid in targeting [38]. However, the low retention and poor stability of EVs post-transplantation limit further application in clinic practice. To enhance the therapeutic effect of MSC-EVs for kidney diseases, EVs are encapsulated in a collagen matrix [39], matrix metalloproteinase-2-sensitive selfassembling peptide hydrogel [40], and arginine-glycineaspartate (RGD) hydrogel [41] to prolong their retention and therefore induce sustained release. Demonstrably, RGD hydrogels interact with EVs mediating by integrin subunits $\alpha v, \beta 3$, and $\beta 8$ [41]. Besides slowing the eliminating process of EVs, encapsulation can assist EVs kidney to attenuate kidney injury by pathological damage reduction, promotion of cell proliferation, inhibition of renal cell apoptosis, amplification of autophagic activation, and enhancing of angiogenesis as well as ameliorating fibrosis [39-41]. It is also found the overexpression of Oct-4 can improve the therapeutic effect of MSC-EVs [42], and hypoxia stimulates the MSCs to secrete more EVs [43]. Erythropoietin-processed MSC-EVs can increase the miRNA content in EVs and therefore may help to enhance the protective effect on the kidney [44].

\section{MSC-EVs and kidney diseases MSC-EVs and AKI}

AKI is prevalent in critically ill patients, even the mortality of those AKI patients not in intensive care units is as high as $10-20 \%$ [45]. There is still a lack of specific and effective therapies for AKI, while stem cell transplantation is promising. Numerous experiments have confirmed the benefits of MSCs in treating AKI, and many methods of enhancing the effect of MSCs have emerged in recent years. For example, IL-17A is found able to increase the percentage of Treg via the COX-2/PGE2 pathway and simulate the immunosuppression function of MSCs [46]; by coating MSCs with antibodies directed against kidney injury molecule-1, the retention of MSCs in ischaemic kidney is prolonged [47]; in the mouse model of cisplatin-induced AKI, MSCs are injected directly to the aorta using a minimally invasive technique, which improves the effective rate of utilisation of MSCs [48].

As the research progresses, evidence shows that MSCEVs play a major role in treating AKI. MSC-EVs can relieve AKI by inhibiting oxidation, apoptosis, and inflammation and regulating angiogenesis, cell cycle, regeneration, autophagy, and proliferation [49-54] (Fig. 2). However, for AKIs with different pathogeneses, the signal substances transferred from MSC-EVs to the target cells exhibit their unique characteristics. The main pathogeneses of AKI include renal toxicity of drugs, ischaemic-reperfusion injury (IRI) caused by transplantation, and sepsis. Correspondingly, experimental AKI models are mainly induced by cisplatin, gentamicin, paraquat, ischaemia-reperfusion (I/R) by occlusion of the unilateral or bilateral renal arteries, and sepsis caused by caecal ligation and puncture (CLP). The mechanisms of MSC-EVs in different AKI models in this review are summarised in Table 1.

\section{I/R-induced kidney injury}

$I / R$ is a common pathogenesis of AKI. In animal trials, $I / R$ models are generally established by occluding the unilateral or bilateral renal arteries and veins and then providing oxygen supply. Previous research indicated that huMSC-EVs can alleviate renal IRI in rats independent of the effect of promoting angiogenesis induced by the hypoxia-inducible factor-1 [49]. MSC-EVs can also inhibit macrophages in the $I / R$ model via various pathways to relieve AKI. In the experiments performed by Zou et al., MVs derived from human Wharton's jelly MSCs (hWJMSCs) suppress the expression of the renal chemokine CX3CL1 by miR-15a/15b/16 and reduce the number of CD68+ macrophages [55]. Shen et al. found that the C-C chemokine receptor-2 expressed on BMMSC-Exos inhibits the recruitment and activation of CCL2 for macrophages by acting as a decoy to bind ligand CCL2 [56].

Apoptosis is closely related to IRI. Gu et al. verified, through in vivo and in vitro experiments, that EVs derived from hWJMSCs (hWJMSC-EVs) decrease apoptosis of renal tubular epithelial cells (TECs) by inhibiting mitochondria fission using miR-30 [57]. Moreover, Li et al. stated that MSC-Exo slowed the progression of IRI by inhibiting expressions of inflammatory factors (IL-6, TNF$\alpha$, NF-kappa B, and IFN- $\gamma$ ) and apoptosis-related factors (caspase-9, cleaved caspase-3, Bax, and Bcl-2) [50]. 


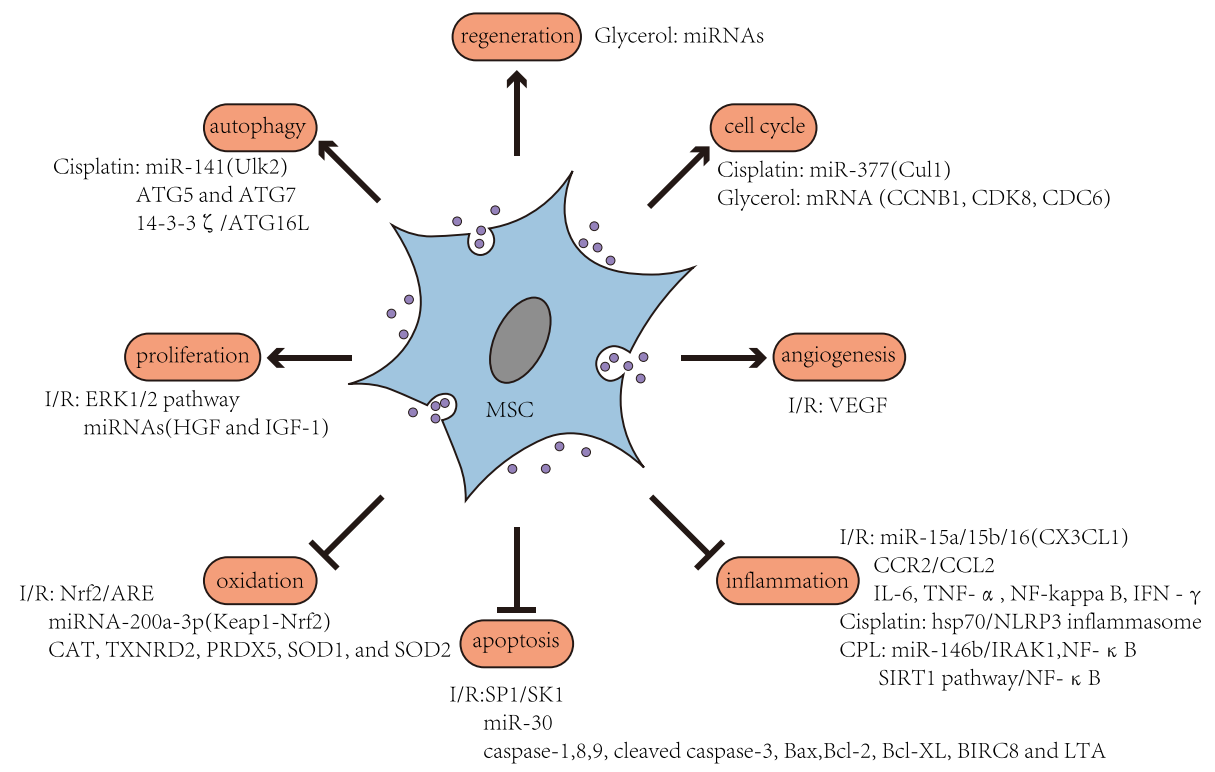

Fig. 2 Functional pathways of MSC-EVs in different AKI models. MSC-EVs can relieve AKI by inhibiting oxidation, apoptosis, and inflammation and regulating angiogenesis, cell cycle, regeneration, autophagy, and proliferation. MSCs, mesenchymal stem cells; EVs, extracellular vesicles; AKI, acute kidney injury; I/R, ischaemia-reperfusion; CLP, caecal ligation and puncture

Antioxidation is an effective measure to alleviate I/R. Zhang et al. revealed that hWJMSC-EVs play their antioxidative effect by activating the nuclear factor-erythroid 2-related factor Nrf2/ARE [57]. Thereafter, experiments by Cao et al. demonstrated that BMMSC-EVs activate the Keap1-Nrf2 signalling pathway in the TECs by transferring miRNA-200a-3p, thus modulating the mitochondria to play an antioxidative role [51].

\section{Cisplatin-induced AKI model}

Models of AKI induced by drugs are generally established through the induction of cisplatin. Using the cisplatin-induced AKI model, Bruno et al. found that BMMSC-MVs protect the kidney by inducing expressions of anti-apoptotic genes (Bcl-XL, Bcl2, and BIRC8) in TECs and inhibiting expressions of pro-apoptotic genes (Casp1, Casp8, and LTA) [58]. Zhou et al. concluded that huMSC-Exos can stimulate proliferation of nephrocytes in vivo and in vitro by inducing the phosphorylation and activation of extracellular regulated kinase (ERK) $1 / 2$ pathway [52]. de Almeida et al. highlighted the function of ADMSC-MVs in regulating injured cells and the specific miRNA-mRNA network. For example, miR-141 targets Ulk2 to regulate autophagy and miR-377 targets Cul1 to modulate the cell cycle [53]. Wang et al. discovered that huMSC-Exo preprocessing can prevent cisplatin-induced renal toxicity in vivo and in vitro by activating autophagy [59]. Jia et al. conducted two studies and identified $14-3-3 \zeta$ as a new mechanism of autophagy activated by huMSC-Exos:
14-3-3 $\zeta$ acts on ATG16L, which activates autophagy and therefore prevents cisplatin-induced AKI [60, 61]. Ullah et al. recently proposed that BMMSC-EVs and pulsed focused ultrasound both alleviate cisplatin-induced cell injury by inhibiting hsp70-mediated NLRP3 inflammasomes [62].

\section{AKI model due to myolysis induced by glycerinum}

In recent years, the AKI model due to myolysis induced by glycerinum also has received much attention. In such a model, Bruno et al. found that BMMSC-EVs (mainly Exos) are enriched in specific mRNA (CCNB1, CDK8, and CDC6), which influence the onset and progression of cell cycles. The enriched miRNAs promote proliferation by growth factors (HGF and IGF-1) and therefore relieve AKI [63]. Through bioengineering, Tapparo et al. increased specific miRNAs (hsa-miR-10a-5p, hsa-miR-29a3p, hsa-miR-127-3p, and hsa-miR-486-5p) in BMMSCEVs to simulate the pro-regenerative effect thereof and alleviate the kidney injury induced by glycerinum [54].

\section{CLP}

The AKI model prepared by CLP simulates the sepsisrelated AKI of critically ill patients. In mice with sepsis, Zhang et al. revealed that huMSC-Exos inhibit NF-kB activity by upregulating miR-146b level while downregulating interleukin-1 receptor-associated kinase expression [64]. Similarly, Gao et al. stated that ADMSC-Exo can regulate NF- $\mathrm{KB}$ via the SIRT1 signalling pathway, thus inhibiting inflammation of sepsis-related AKI [65]. 


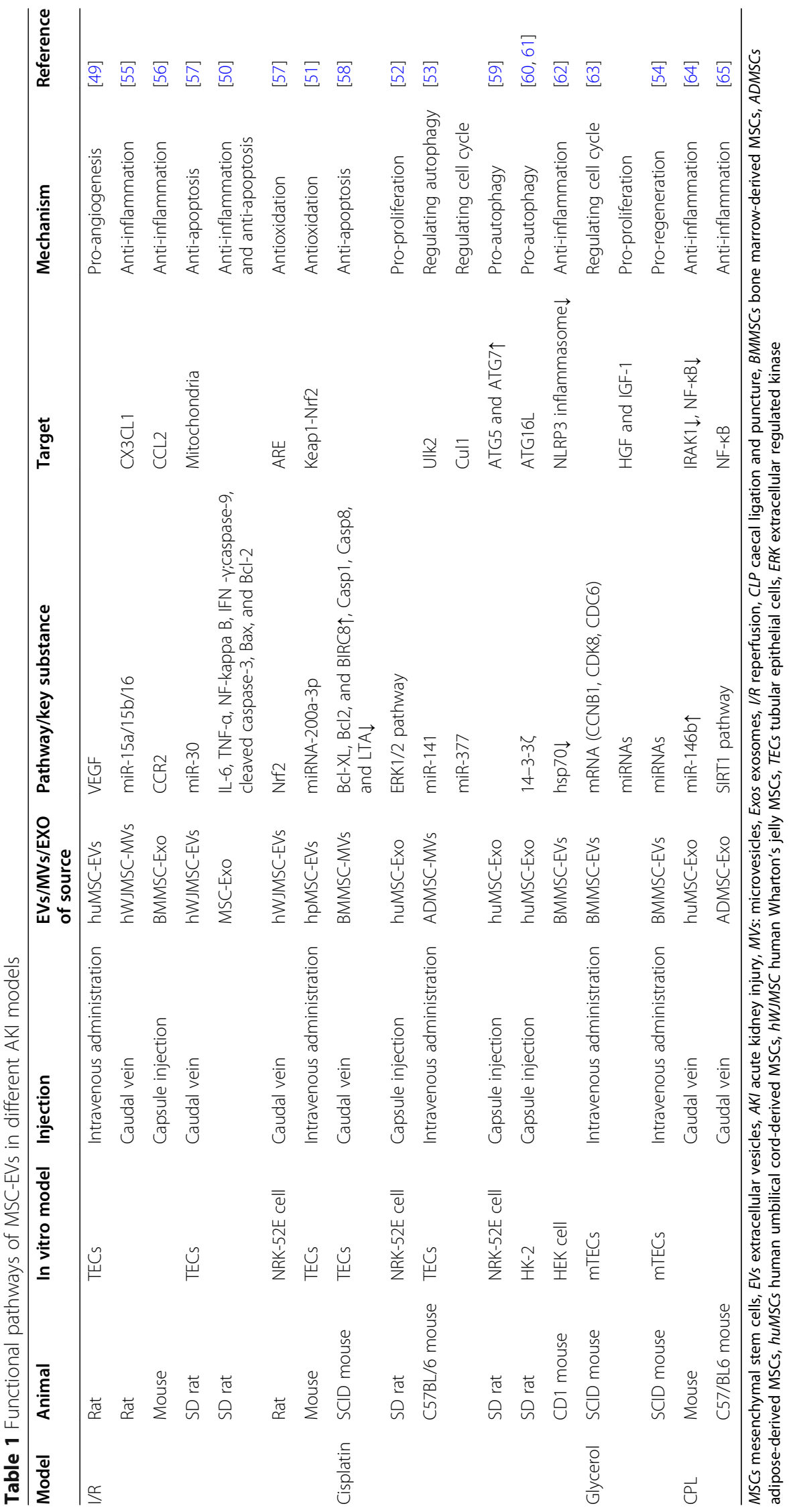




\section{MSC-EVs and CKD}

There is new evidence proving that, in many cases, AKI may evolve into CKD [66]. After developing AKI, the additional risks of contracting end-stage renal diseases and CKD were estimated to be increased by 0.4 and 10 cases annually in every 100 AKI patients, respectively [67]. CKD is characterised by progressive irreversible fibrosis of the renal parenchyma. Many diseases can evolve into CKD, including AKI, diabetes, atherosclerosis, and nephrotic syndromes. Numerous evidences have been obtained in relation to the treatment of CKD with MSCs in pre- and post-clinical trials. It has been found in recent research that melatonin preconditioning enhances the treatment ability of MSCs in autologous and allogeneic transplantation $[68,69]$. In a clinical trial involving an 18-month follow-up of seven eligible CKD patients, the single-dose autologous MSCs have been proven to be safe and tolerable in CKD patients [70]. Researchers then found that the conditioned medium of huMSCs relieves the fibrosis induced by unilateral ureteral obstruction (UUO) by pro-proliferation and antiapoptosis [71]. To date, many preclinical studies have proven that MSC-EVs are effective in treating CKD.

In the mouse model of chronic renal toxicity due to cyclosporine, the conditioned medium depleted of EVs, MSC-EVs, and EVs can improve the prognosis of kidney diseases [72]. In the aristolochic acid nephropathy model, MSC-EVs significantly reduce expressions of pro-fibrogenic genes such as $\alpha$-SMA, TGF $\beta 1$, and Colla1 [73]. In the UUO model, Wang et al. found that BMMSC-Exos alleviate renal interstitial fibrosis by inhibiting TGF- $\beta 1$ with miRNA-let7c [74]. Recently, some researchers found (in the mouse model) that huMSCExos relieve renal interstitial fibrosis by suppressing the ROS-mediated P38MAPK/ERK pathway [75]. Chen et al. proposed that the glial-derived neurotrophic factormodified ADMSC-Exos stimulate the perivascular capillaries in tubulointerstitial fibrosis by activating the SIRT1/eNOS pathway [76]. In addition, previous research also suggested that ADMSC-Exos upregulate the expression of the transcription factor Sox 9 of TECs, and the offspring of $\mathrm{Sox}^{+}$cells facilitate regeneration of renal tubules rather than fibrotic transformation, thus slowing the AKI-CKD transition $[17,77]$.

\section{MSC-EVs and DN}

$\mathrm{DN}$ is the main pathogenesis for ESRD. There are numerous investigations evincing that MSC transplantation can slow the progression of DN. A randomised controlled trial reported that it is safe and feasible to use the mesenchymal precursor cells in subjects of type 2 diabetes [78]; however, there are immune rejection problems in allogeneic transplantation and damage induced by hyperglycaemia to autologous MSCs. To solve these problems, Nagaishi et al. innovatively used Wharton's jelly extract supernatant to improve the morphologies, proliferation capacity, and cellular mobilisation capacity of diabetes-derived BMMSCs, which enables effective autologous transplantation [79]. Recently, some researchers also attempted to co-culture MSCs with peritoneal macrophages [80] and to modify MSCs with angiotensin-converting enzyme 2 [81] to improve the treatment capacity of MSCs for DN.

The mechanism of MSC-EVs, as a new means for treating $\mathrm{DN}$, is under constant exploration. Gallo et al. found that MSC/human liver stem cell (HLSC)-EVs can protect mesangial cells from damages induced by hyperglycaemia through the transfer of miR-222 [82]. Also, hyperglycaemia can directly induce the injury of podocytes. The pathological changes of podocytes are closely related to the progression of DN. MSC-EVs are able to protect podocytes and other renal cells by diverse means, including anti-apoptosis, anti-fibrosis, and pro-autophagic effects, thus treating DN (Fig. 3). Duan et al. revealed that the Exo isolated from the conditioned medium of human urine-derived stem cells inhibits the expression of VEGFA and the apoptosis of podocytes by miRNA-16-5p, thereby relieving DN [83]. It is proven by Duan et al. that ADSCEV miRNA-26a-5p suppresses the hyperglycaemiainduced apoptosis of podocytes in mice by downregulating the TLR4 and NF-kB/VEGFA signalling pathways [84]. Anti-fibrosis is also a major mechanism invoked in DN treatment with MSC-EVs. Zhong et al. reported that MSC-MVs are capable of suppressing cell cycle inhibitors P15 and P19 in vivo and in vitro via miRNA-451a, restarting the cell cycle, and thus reversing the EMT and interstitial fibrosis [85]. Grange et al. considered that EVs of HLSCs and MSCs can inhibit and reverse the progression of glomerular and tubule-interstitial fibrosis in the $\mathrm{DN}$ mouse models by downregulating fibrosis-related gene Serpia1a, the FAS ligand, CCL3, TIMP1, MMP3, type I collagen, and Snail [86]. Jin et al. verified that the ADMS C-Exo weakens the EMT of podocytes by suppressing the genetic transcription of ZEB2 by miRNA-215-5p [87]. Autophagy has also been recently considered as a mechanism to delay DN. Ebrahim et al. confirmed that MSC-Exos enhance autophagy and then slow the progression of $\mathrm{DN}$ via the mTOR signalling pathway [88]. Jin et al. further showed that the ADMSC-Exo can inhibit the Smad1/ mTOR signalling pathway by miRNA-486, which promotes autophagy and inhibits apoptosis in podocytes, thus ameliorating the symptoms of DN [89]. Details of the aforementioned trials are summarised in Table 2.

\section{MSC-EVs and atherosclerotic renovascular diseases}

Atherosclerosis is the primary cause of renal artery stenosis. Atherosclerotic renovascular disease (ARVD) can induce chronic renal ischaemia and further lead to 


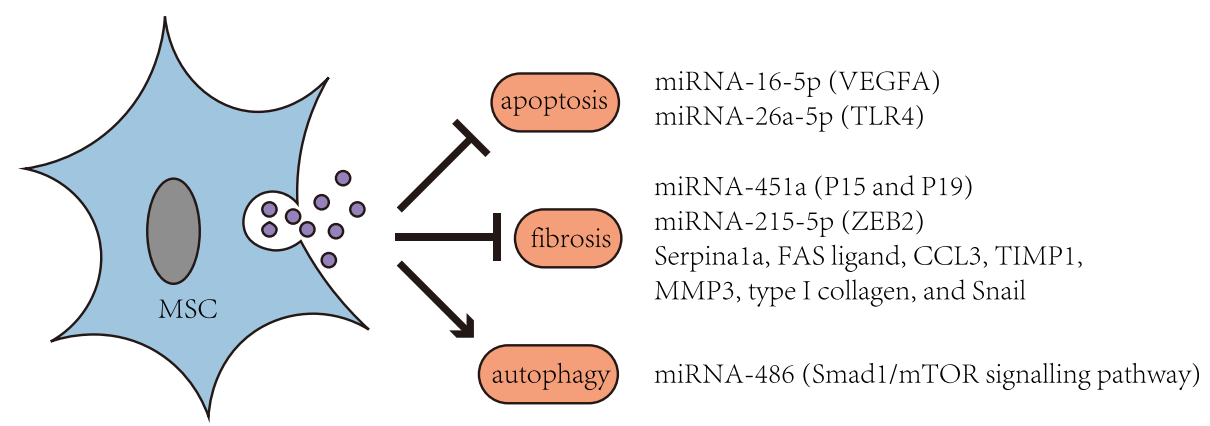

Fig. 3 Functional pathways of MSC-EVs in DN. MSC-EVs are able to protect podocytes and other cells by diverse means, including anti-apoptosis, anti-fibrosis, and pro-autophagic effects, thus treating DN. MSCs, mesenchymal stem cells; EVs, extracellular vesicles; DN, diabetic nephropathy

fibrosis, which develops to ESRD. Percutaneous transluminal renal angioplasty is a common surgery for treating ARVD; however, it is difficult to restore functions of the atrophic kidney. Animal experiments have confirmed that the combination of MSCs with ARVD to treat atherosclerotic renal artery stenosis helps to restore functions of the kidney [90]. Thereafter, several clinical trials have evinced the safety of infusing autologous ADMSCs in the treatment of ARVD [91-93]. Following this, ADMSC-EVs have also become the focus of recent research. In the model of unilateral renovascular disease complicating metabolic syndrome (MetS), Eirin et al. proved that the autologous ADMSC-EVs improve the renal microvascular system in pigs with metabolic renal vascular diseases [94]. Besides this, Simeoni et al. further identified the miRNA in MSC-EVs as an important target for ARVD [95]. In addition, MSC-EVs were also found to enhance the advantages of Treg by TGF- $\beta$ therein and therefore improve the functions of the kidney with renal artery stenosis in the MetS+RAS model [96]. Autologous ADMSC-EVs can also prompt the transformation of phenotypes of macrophages from M1 to M2 via IL-10, so as to relieve renal artery stenosis [97].
At the same time, some researchers proposed that MSC-Exos can only partially relieve ageing kidney induced by renal artery stenosis [98]. MetS is able to change the amount of loading of miRNA on EVs, upregulate ageing-related miRNA in EVs, and even limit the use of EVs in exogenous regenerative therapy through abnormal transcription [99-101]. Zhao et al. found that autologous ADMSCs can better preserve microcirculation through comparative studies, while ADMSC-EVs perform better in retaining intactness of nephrocytes and reducing necrosis [102]. In summary, the application value of MSC-EVs in the treatment of ARVD remains in dispute, and further research is warranted to reveal their efficacy.

\section{MSC-EVs and kidney transplantation}

Kidney transplantation is the preferred treatment method for end-stage renal failure patients. The shortage of donor organs and the half-life of the transplant limit the therapy [4]. In addition, ischaemia-induced AKI is widely seen in kidney transplantation due to the time available for the development of ischaemia given the delay between the accession of the kidney from the donor to renal ischaemia reperfusion in receptors [103].

Table 2 Functional pathways of MSC-EVs in DN models

\begin{tabular}{|c|c|c|c|c|c|c|c|c|}
\hline Model & Animal & $\begin{array}{l}\text { In vitro } \\
\text { model }\end{array}$ & Injection & $\begin{array}{l}\text { EVs/MVs/EXO } \\
\text { of source }\end{array}$ & $\begin{array}{l}\text { Pathway/key } \\
\text { substance }\end{array}$ & Target & Mechanism & Reference \\
\hline \multirow[t]{2}{*}{ STZ } & SD rat & HPDCs & Tail vein & hUSC-EXO & miRNA-16-5p & VEGFA podocytes & Anti-apoptosis & [83] \\
\hline & $\begin{array}{l}\text { C57BL/KsJ db/m } \\
\text { mouse }\end{array}$ & MP5 cell & Tail vein & ADMSC-EVs & miRNA-26a-5p & TLR4 & Anti-apoptosis & [84] \\
\hline STZ & Babl/c mouse & HK-2 cell & Tail vein & huMSC-MVs & miRNA-451a & P15 and P19 & Anti-fibrosis & [85] \\
\hline \multirow[t]{2}{*}{ STZ } & NSG mouse & & Tail vein & HLSC/MSC EVS & $\begin{array}{l}\text { Serpina1a, FAS ligand, } \\
\text { CCL3, TIMP1, MMP3, } \\
\text { type I collagen, and Snail }\end{array}$ & & Anti-fibrosis & [86] \\
\hline & & MPC5 cell & & ADMSC-Exo & miRNA-215-5p & ZEB2 & Anti-fibrosis & {$[87]$} \\
\hline \multirow[t]{2}{*}{ STZ } & Albino rat & & Tail vein & BMMSC-EXO & & mTOR pathway & Inducing autophagy & [88] \\
\hline & & MPC5 cell & & ADMSC-ExO & miRNA-486 & $\begin{array}{l}\text { Smad1/mTOR } \\
\text { signalling pathway }\end{array}$ & Pro-autophagy & [89] \\
\hline
\end{tabular}


This is also a major cause of the delayed functions of the transplant. To solve these problems, static cold storage, hypothermic machine perfusion (HMP), and several new drug candidates targeting ischaemia and reperfusion are under study [104]. The work of del Rio et al. verified that HMP and normothermic regional perfusion are preferable to static cold storage [105]. Also, researchers are devoted to find other effective ways to complement the current techniques.

A trial involving 105 Chinese kidney transplantation subjects who received autologous MSCs in the reperfusion of the transplanted kidney suggests that it is feasible and safe to use MSCs in kidney transplantation [106]; however, a similar trial conducted by another research team recently found that the post-operative complications of renal transplantation, infectious complications, kidney functions, rejection frequency, and survival time all do not show statistical differences with the control in the 1-year follow-up [107]. Therefore, the protective effect of MSC-EVs in transplanted kidney remains a matter of dispute. Gregorini et al. proved that adding MSCs/ EVs to the Belzer solution in the HMP period can protect the kidney from ischaemic injury by preserving the enzymatic mechanism essential to cell viability [108]. Experiments by Koch et al. indicated that MSC-EVs regulate the immunoreaction to allogeneic kidney transplants to some extent [109]. Significantly different from this, by establishing a rat model of heterotopic kidney transplantation, Jose Ramirez-Bajo et al. found that autologous MSCs prolong the survival time of transplants and subjects in the rat model of renal rejection, while EVs do not [110]. This topic is rarely studied, and further research is required before a conclusion can be drawn.

\section{Problems and prospects}

In previous research, MSCs have been found to play their positive roles in treating various kidney diseases. For example, MSC-CM relieves the experimental anti-glomerular basement membrane glomerulonephritis by virtue of the M2 macrophage-mediated anti-inflammatory action [111]. In systemic lupus erythematosus (SLE), allogeneic MSC transplantation mitigates kidney injury [112]. Clinical trials also show that it is both safe and feasible to treat SLE patients with allogeneic MSCs from healthy donors [113]. In the model of nephrotic syndrome induced by Adriamycin, MSCs mainly play their role in kidney repair by regulating inflammation [114]. Moreover, healthy donors and idiopathic nephrotic syndrome (INS) patients do not exhibit obvious differences in the functions and morphologies of MSCs, which indicates that MSCs can be used for treating INS with autologous cells [115]. MSC treatment exerts beneficial effects on IgAN by the mechanism of paracrine that modulates the balance of the Th1/Th2 cytokine [116]. In the rat model of anti-Thy1.1-induced glomerulonephritis, hypoxicpreconditioned MSCs decrease glomerular apoptosis, autophagy, and inflammation through signal transduction of HIF1 $\alpha / V E G F / N r f 2$ [117]. MSCs relieve renal hypertension and improve kidney function in the 2-kidney, 1-clip model [118]. No adverse events and severe adverse events were observed clinically when treating anti-body against antineutrophil cytoplasmic antibody-associated vasculitis [119] and autosomal dominant polycystic kidney disease [120] with autologous mesenchymal stromal cells. Existing research also proposes that MSCs possibly relieve focal segmental glomerulosclerosis via IL-22 [121].

In conclusion, both animal models and clinical trials provided much evidence of the potential of MSCs in the treatment of kidney diseases; however, there is little research into the treatment of the aforementioned diseases with MSC-EVs, which remains to be explored. This is possibly because the separation, purification, and mass production of EVs remain a challenge; moreover, the mechanism by which MSC-EVs treat kidney diseases has not been elucidated. In addition, in consideration of optimal source, appropriate dosage, and appropriate route of administration of EVs, further research needs to be undertaken to assess the efficacy of the application of MSC-EVs to clinical treatment of kidney diseases.

\section{Conclusion}

In this review, we summarised the recent advances of complex and critical effects of MSC-EVs in kidney diseases, including AKI, CKD, DN, ARVD, and kidney transplantation. A large number of articles support that most kidney diseases can benefit from MSC-EVs; however, the effects of kidney transplantation are still controversial. Although MSC-EVs isolated from different sources show great promise as therapeutic agents for kidney diseases in animal studies and preclinical trials, further studies are necessary since only few clinical works have been described at the moment.

\section{Abbreviations \\ MSCs: Mesenchymal stem cells; EVs: Extracellular vesicles; MSC-EVs: MSC- derived EVs; CKD: Chronic kidney disease; DN: Diabetic nephropathy; ARVD: Atherosclerotic renovascular disease; AKI: Acute kidney injury; BMMSCs: Bone marrow-derived MSCs; ADMSCs: Adipose-derived MSCs; huMSCs: Human umbilical cord-derived MSCs; mRNA: Messenger ribose nucleic acid; miRNA: Micro-ribose nucleic acid; MVs: Microvesicles; Exos: Exosomes; MVBs: Multivesicular bodies; RGD: Arginine-glycine-aspartate; IRI: Ischaemic reperfusion injury; I/R: Ischaemia-reperfusion; CLP: Caecal ligation and puncture; hWJMSCs: Human Wharton's jelly MSCs; hWJMSC- EVs: EVs derived from hWJMSCs; TECs: Tubular epithelial cells; \\ ERK: Extracellular regulated kinase; UUO: Unilateral ureteral obstruction; HLSC: Human liver stem cell; ARVD: Atherosclerotic renovascular disease; MetS: Metabolic syndrome; HMP: Hypothermic machine perfusion; SLE: Systemic lupus erythematosus; INS: Idiopathic nephrotic syndrome}

\section{Acknowledgements}

We are grateful to the National Natural Science Foundation of China (Grant No. 81970663) and the Natural Science Foundation of Liaoning Province (Grant No. 2019-BS-277). 


\section{Authors' contributions}

Lina Yang contributed to the study design. Yuling Huang and Lina Yang performed the data collection, analysed the data, and wrote the article. All authors read and approved the final manuscript.

\section{Funding}

This research was supported by the National Natural Science Foundation of China (Grant No. 81970663) and the Natural Science Foundation of Liaoning Province (Grant No. 2019-BS-277).

\section{Availability of data and materials}

The datasets used and analysed in the present research are available from the corresponding author upon reasonable request.

\section{Declarations}

Ethics approval and consent to participate

Not applicable.

\section{Consent for publication}

Not applicable.

\section{Competing interests}

The authors declare that they have no competing interests.

\section{Received: 4 January 2021 Accepted: 15 March 2021}

Published online: 31 March 2021

\section{References}

1. Fraser SDS, Roderick PJ. Kidney disease in the Global Burden of Disease Study 2017. Nat Rev Nephrol. 2019;15(4):193-4. https://doi.org/10.1038/s41 581-019-0120-0.

2. Chade AR. Small vessels, big role: renal microcirculation and progression of renal injury. Hypertension. 2017;69(4):551-63. https://doi.org/10.1161/ HYPERTENSIONAHA.116.08319.

3. Kramer A, Pippias M, Noordzij M, Stel VS, Afentakis N, Ambuhl PM, et al. The European Renal Association - European Dialysis and Transplant Association (ERA-EDTA) Registry Annual Report 2015: a summary. Clin Kidney J. 2018; 11(1):108-22. https://doi.org/10.1093/ckj/sfx149.

4. Bastani B. The present and future of transplant organ shortage: some potential remedies. J Nephrol. 2020;33(2):277-88. https://doi.org/10.1007/s4 0620-019-00634-X.

5. Squillaro T, Peluso G, Galderisi U. Clinical trials with mesenchymal stem cells: an update. Cell Transplant. 2016;25(5):829-48. https://doi.org/10.3727/0963 $68915 \times 689622$.

6. Abbaszadeh H, Ghorbani F, Derakhshani M, Movassaghpour A, Yousefi M. Human umbilical cord mesenchymal stem cell-derived extracellular vesicles: a novel therapeutic paradigm. J Cell Physiol. 2020;235(2):706-17. https://doi. org/10.1002/jcp.29004.

7. da Silva ML, Chagastelles PC, Nardi NB. Mesenchymal stem cells reside in virtually all post-natal organs and tissues. J Cell Sci. 2006:119(11):2204-13.

8. Zuk PA, Zhu M, Mizuno H, Huang J, Futrell JW, Katz AJ, Benhaim P, Lorenz $\mathrm{HP}$, Hedrick MH. Multilineage cells from human adipose tissue: implications for cell-based therapies. Tissue Eng. 2001;7(2):211-28. https://doi.org/10.1 089/107632701300062859.

9. Erices A, Conget $\mathrm{P}$, Minguell JJ. Mesenchymal progenitor cells in human umbilical cord blood. Br J Haematol. 2000;109(1):235-42. https://doi.org/10.1 046/j.1365-2141.2000.01986x.x

10. in't Anker PS, Scherjon SA, Kleijburg-van der Keur C, de Groot-Swings G, Claas FHJ, Fibbe WE, et al. Isolation of mesenchymal stem cells of fetal or maternal origin from human placenta. Stem Cells. 2004;22(7):1338-45.

11. Bharadwaj S, Liu G, Shi Y, Wu R, Yang B, He T, Fan Y, Lu X, Zhou X, Liu H, Atala A, Rohozinski J, Zhang Y. Multipotential differentiation of human urine-derived stem cells: potential for therapeutic applications in urology. Stem Cells. 2013;31(9):1840-56. https://doi.org/10.1002/stem.1424.

12. Caplan H, Olson SD, Kumar A, George M, Prabhakara KS, Wenzel P, Bedi S, Toledano-Furman NE, Triolo F, Kamhieh-Milz J, Moll G, Cox CS Jr. Mesenchymal stromal cell therapeutic delivery: translational challenges to clinical application. Front Immunol. 2019;10 https://doi.org/10.3389/fimmu.2 019.01645 .
13. Sierra-Parraga JM, Merino A, Eijken M, Leuvenink H, Ploeg R, Moller BK, et al. Reparative effect of mesenchymal stromal cells on endothelial cells after hypoxic and inflammatory injury. Stem Cell Res Ther. 2020;11(1):352.

14. Rangel EB, Gomes SA, Kanashiro-Takeuchi R, Saltzman RG, Wei C, Ruiz P, Reiser J, Hare JM. Kidney-derived c-kit(+) progenitor/stem cells contribute to podocyte recovery in a model of acute proteinuria. Sci Rep. 2018;8(1):14723. https://doi.org/10.1038/s41598-018-33082-x.

15. Hauger $O$, Frost EE, van Heeswijk R, Deminiere C, Xue R, Delmas $Y$, et al. MR evaluation of the glomerular homing of magnetically labeled mesenchymal stem cells in a rat model of nephropathy. Radiology. 2006;238(1):200-10. https://doi.org/10.1148/radiol.2381041668.

16. Ma H, Wu Y, Zhang W, Dai Y, Li F, Xu Y, Wang Y, Tu H, Li W, Zhang X. The effect of mesenchymal stromal cells on doxorubicin-induced nephropathy in rats. Cytotherapy. 2013;15(6):703-11. https://doi.org/10.1016/j.jcyt.2013.02. 002.

17. Zhang K, Chen S, Sun H, Wang L, Li H, Zhao J, Zhang C, Li N, Guo Z, Han Z, Han ZC, Zheng G, Chen X, Li Z. In vivo two-photon microscopy reveals the contribution of Sox $9^{+}$cell to kidney regeneration in a mouse model with extracellular vesicle treatment. J Biol Chem. 2020;295(34):12203-13. https:// doi.org/10.1074/jbc.RA120.012732.

18. Ullah M, Liu DD, Thakor AS. Mesenchymal stromal cell homing: mechanisms and strategies for improvement. Iscience. 2019;15:421-38. https://doi.org/1 0.1016/j.isci.2019.05.004.

19. Hocking AM. The role of chemokines in mesenchymal stem cell homing to wounds. Adv Wound Care. 2015;4(11):623-30. https://doi.org/10.1089/ wound.2014.0579.

20. de Witte SFH, Luk F, Parraga JMS, Gargesha M, Merino A, Korevaar SS, et al. Immunomodulation by therapeutic mesenchymal stromal cells (MSC) is triggered through phagocytosis of MSC by monocytic cells. Stem Cells. 2018;36(4):602-15. https://doi.org/10.1002/stem.2779.

21. Schrepfer S, Deuse T, Reichenspurner H, Fischbein MP, Robbins RC, Pelletier MP. Stem cell transplantation: the lung barrier. Transplant Proc. 2007;39(2): 573-6. https://doi.org/10.1016/j.transproceed.2006.12.019.

22. Zhao L, Hu C, Han F, Wang J, Chen J. Regenerative abilities of mesenchymal stem cells via acting as an ideal vehicle for subcellular component delivery in acute kidney injury. J Cell Mol Med. 2020;24(9):4882-91. https://doi.org/1 $0.1111 / \mathrm{jcmm} .15184$.

23. He CJ, Zheng S, Luo Y, Wang B. Exosome theranostics: biology and translational medicine. Theranostics. 2018;8(1):237-55. https://doi.org/10.71 50/thno.21945.

24. Colombo M, Raposo G, Thery C. Biogenesis, secretion, and intercellular interactions of exosomes and other extracellular vesicles. Annu Rev Cell Dev Biol. 2014;30(1):255-89. https://doi.org/10.1146/annurev-cellbio-101 512-122326

25. Kalluri R, LeBleu VS. The biology, function, and biomedical applications of exosomes. Science. 2020;367(6478):640.

26. Sonoda $\mathrm{H}$, Lee BR, Park KH, Nihalani D, Yoon JH, Ikeda M, et al. miRNA profiling of urinary exosomes to assess the progression of acute kidney injury. Sci Rep. 2019;9

27. Castellani C, Burrello J, Fedrigo M, Burrello A, Bolis S, Di Silvestre D, et al. Circulating extracellular vesicles as non-invasive biomarker of rejection in heart transplant. J Heart Lung Transplant. 2020;39(10):1136-48. https://doi. org/10.1016/j.healun.2020.06.011.

28. Zou X, Kwon SH, Jiang K, Ferguson CM, Puranik AS, Zhu X, Lerman LO. Renal scattered tubular-like cells confer protective effects in the stenotic murine kidney mediated by release of extracellular vesicles. Sci Rep. 2018; 8(1):1263. https://doi.org/10.1038/s41598-018-19750-y.

29. Dominguez JM II, Dominguez JH, Xie D, Kelly KJ. Human extracellular microvesicles from renal tubules reverse kidney ischemia-reperfusion injury in rats. PLoS One. 2018;13(8)

30. Ranghino A, Bruno S, Bussolati B, Moggio A, Dimuccio V, Tapparo M, Biancone L, Gontero P, Frea B, Camussi G. The effects of glomerular and tubular renal progenitors and derived extracellular vesicles on recovery from acute kidney injury. Stem Cell Res Ther. 2017;8(1):24. https://doi.org/10.1186/ s13287-017-0478-5.

31. De Chiara L, Famulari ES, Fagoonee S, van Daalen SKM, Buttiglieri S, Revelli A, et al. Characterization of human mesenchyma stem cells isolated from the testis. Stem Cells Int. 2018;2018:1-9. https://doi.org/10.1155/2018/49103 04.

32. Grange C, Papadimitriou E, Dimuccio V, Pastorino C, Molina J, O'Kelly R, et al. Urinary extracellular vesicles carrying Klotho improve the recovery of 
renal function in an acute tubular injury model. Mol Ther. 2020;28(2):490502. https://doi.org/10.1016/j.ymthe.2019.11.013.

33. Garcia-Manrique P, Matos M, Gutierrez G, Pazos C, Carmen B-LM. Therapeutic biomaterials based on extracellular vesicles: classification of bioengineering and mimetic preparation routes. J Extracellular Vesicles. 2018; $7(1)$

34. Baek G, Choi H, Kim Y, Lee H-C, Choi C. Mesenchymal stem cell-derived extracellular vesicles as therapeutics and as a drug delivery platform. Stem Cells Transl Med. 2019;8(9):880-6. https://doi.org/10.1002/sctm.18-0226.

35. Ha D, Yang N, Nadithe V. Exosomes as therapeutic drug carriers and delivery vehicles across biological membranes: current perspectives and future challenges. Acta Pharm Sin B. 2016;6(4):287-96. https://doi.org/10.101 6/j.apsb.2016.02.001.

36. Melzer C, Rehn V, Yang Y, Bahre H, von der Ohe J, Hass R. Taxol-loaded MSC-derived exosomes provide a therapeutic vehicle to target metastatic breast cancer and other carcinoma cells. Cancers. 2019;11(6)

37. Tang T-T, Wang B, Lv L-L, Liu B-C. Extracellular vesicle-based nanotherapeutics: emerging frontiers in anti-inflammatory therapy. Theranostics. 2020;10(18):8111-29. https://doi.org/10.7150/thno.47865.

38. Mathieu M, Martin-Jaular L, Lavieu G, Thery C. Specificities of secretion and uptake of exosomes and other extracellular vesicles for cell-to-cell communication. Nat Cell Biol. 2019;21(1):9-17. https:/doi.org/10.1038/s41556-018-0250-9.

39. Liu Y, Cui J, Wang H, Hezam K, Zhao X, Huang H, et al. Enhanced therapeutic effects of MSC-derived extracellular vesicles with an injectable collagen matrix for experimental acute kidney injury treatment. Stem Cell Res Ther. 2020;11(1)

40. Zhou Y, Liu S, Zhao M, Wang C, Li L, Yuan Y, Li L, Liao G, Bresette W, Zhang J, Chen Y, Cheng J, Lu Y, Liu J. Injectable extracellular vesicle-released selfassembling peptide nanofiber hydrogel as an enhanced cell-free therapy for tissue regeneration. J Control Release. 2019;316:93-104. https://doi.org/10.1 016/j.jconrel.2019.11.003.

41. Zhang C, Shang Y, Chen X, Midgley AC, Wang Z, Zhu D, Wu J, Chen P, Wu L, Wang $X$, Zhang K, Wang H, Kong D, Yang Z, Li Z, Chen X. Supramolecular nanofibers containing arginine-glycine-aspartate (RGD) peptides boost therapeutic efficacy of extracellular vesicles in kidney repair. ACS Nano. 2020;14(9):12133-47. https://doi.org/10.1021/acsnano.0c05681.

42. Zhang Z-Y, Hou Y-P, Zou X-Y, Xing X-Y, Ju G-Q, Zhong L, Sun J. Oct-4 enhanced the therapeutic effects of mesenchymal stem cell-derived extracellular vesicles in acute kidney injury. Kidney Blood Press Res. 2020 45(1):95-108. https://doi.org/10.1159/000504368.

43. Collino F, Lopes JA, Correa S, Abdelhay E, Takiya CM, Wendt CHC, et al. Adipose-derived mesenchymal stromal cells under hypoxia: changes in extracellular vesicles secretion and improvement of renal recovery after ischemic injury. Cell Physiol Biochem. 2019;52(6):1463-83.

44. Wang Y, Lu X, He J, Zhao W. Influence of erythropoietin on microvesicles derived from mesenchymal stem cells protecting renal function of chronic kidney disease. Stem Cell Res Ther. 2015;6(1):100. https://doi.org/10.1186/ s13287-015-0095-0.

45. Hoste EAJ, Kellum JA, Selby NM, Zarbock A, Palevsky PM, Bagshaw SM, Goldstein SL, Cerdá J, Chawla LS. Global epidemiology and outcomes of acute kidney injury. Nat Rev Nephrol. 2018;14(10):607-25. https:/doi.org/10.1038/s41 581-018-0052-0.

46. Bai M, Zhang L, Fu B, Bai J, Zhang Y, Cai G, Bai X, Feng Z, Sun S, Chen X. IL-17A improves the efficacy of mesenchymal stem cells in ischemic-reperfusion renal injury by increasing Treg percentages by the COX-2/PGE2 pathway. Kidney Int. 2018;93(4):814-25. https://doi.org/10.1016/j.kint.2017.08.030.

47. Zou X, Jiang K, Puranik AS, Jordan KL, Tang H, Zhu X, Lerman LO. Targeting murine mesenchymal stem cells to kidney injury molecule-1 improves their therapeutic efficacy in chronic ischemic kidney injury. Stem Cells Transl Med. 2018;7(5):394-403. https://doi.org/10.1002/sctm.17-0186.

48. Ullah M, Liu DD, Rai S, Razavi M, Choi J, Wang J, et al. A novel approach to deliver therapeutic extracellular vesicles directly into the mouse kidney via its arterial blood supply. Cells. 2020;9(4)

49. Zou X, Gu D, Xing X, Cheng Z, Gong D, Zhang G, Zhu Y. Human mesenchymal stromal cell-derived extracellular vesicles alleviate renal ischemic reperfusion injury and enhance angiogenesis in rats. Am J Trans Res. 2016;8(10):4289-99.

50. Li L, Wang R, Jia $Y$, Rong $R$, Xu M, Zhu T. Exosomes derived from mesenchymal stem cells ameliorate renal ischemic-reperfusion injury through inhibiting inflammation and cell apoptosis. Front Med. 2019;6 https://doi.org/10.3389/fmed.2019.00269.
51. Cao H, Cheng Y, Gao H, Zhuang J, Zhang W, Bian Q, Wang F, du Y, Li Z, Kong D, Ding D, Wang Y. In vivo tracking of mesenchymal stem cell-derived extracellular vesicles improving mitochondria! Function in renal ischemiareperfusion injury. ACS Nano. 2020;14(4):4014-26. https://doi.org/10.1021/a csnano.9b08207.

52. Zhou $Y, X u H, X u$ W, Wang B, Wu H, Tao Y, Zhang B, Wang M, Mao F, Yan Y, Gao S, Gu H, Zhu W, Qian H. Exosomes released by human umbilical cord mesenchymal stem cells protect against cisplatin-induced renal oxidative stress and apoptosis in vivo and in vitro. Stem Cell Res Ther. 2013;4(2):34. https://doi.org/10.1186/scrt194.

53. de Almeida DC, Bassi EJ, Azevedo H, Anderson L, Taemi Origassa CS, Cenedeze MA, et al. A regulatory miRNA-mRNA network is associated with tissue repair induced by mesenchymal stromal cells in acute kidney injury. Front Immunol. 2017;7 https://doi.org/10.3389/fimmu.2016. 00645.

54. Tapparo M, Bruno S, Collino F, Togliatto G, Deregibus MC, Provero P, et al. Renal regenerative potential of extracellular vesicles derived from miRNAengineered mesenchymal stromal cells. Int J Mol Sci. 2019;20(10)

55. Zou X, Zhang G, Cheng Z, Yin D, Du T, Ju G, et al. Microvesicles derived from human Wharton's jelly mesenchymal stromal cells ameliorate renal ischemia-reperfusion injury in rats by suppressing CX3CL1. Stem Cell Res Ther. 2014;5(2):40. https://doi.org/10.1186/scrt428.

56. Shen B, Liu J, Zhang F, Wang Y, Qin Y, Zhou Z, Qiu J, Fan Y. CCR2 positive exosome released by mesenchymal stem cells suppresses macrophage functions and alleviates ischemia/reperfusion-induced renal injury. Stem Cells Int. 2016;2016:1-9. https://doi.org/10.1155/2016/1240301.

57. Gu D, Zou X, Ju G, Zhang G, Bao E, Zhu Y. Mesenchymal stromal cells derived extracellular vesicles ameliorate acute renal ischemia reperfusion injury by inhibition of mitochondrial fission through miR-30. Stem Cells Int. 2016;2016:1-12. https://doi.org/10.1155/2016/2093940.

58. Bruno S, Grange C, Collino F, Deregibus MC, Cantaluppi V, Biancone L, et al. Microvesicles derived from mesenchymal stem cells enhance survival in a lethal model of acute kidney injury. PLoS One. 2012;7(3)

59. Wang B, Jia H, Zhang B, Wang J, Ji C, Zhu X, Yan Y, Yin L, Yu J, Qian H, Xu W. Pre-incubation with hucMSC-exosomes prevents cisplatin-induced nephrotoxicity by activating autophagy. Stem Cell Res Ther. 2017;8(1):75. https://doi.org/10.1186/s13287-016-0463-4.

60. Jia H, Liu W, Zhang B, Wang J, Wu P, Tandra N, Liang Z, Ji C, Yin L, Hu X, Yan Y, Mao F, Zhang X, Yu J, Xu W, Qian H. HucMSC exosomes-delivered 14-3-3 zeta enhanced autophagy via modulation of ATG16L in preventing cisplatin-induced acute kidney injury. Am J Transl Res. 2018;10(1):101-13.

61. Wang J, Jia H, Zhang B, Yin L, Mao F, Yu J, Ji C, Xu X, Yan Y, Xu W, Qian H. HucMSC exosome-transported 14-3-3 zeta prevents the injury of cisplatin to HK-2 cells by inducing autophagy in vitro. Cytotherapy. 2018;20(1):29-44. https://doi.org/10.1016/j.jcyt.2017.08.002.

62. Ullah M, Liu DD, Rai S, Concepcion W, Thakor AS. HSP70-mediated NLRP3 inflammasome suppression underlies reversal of acute kidney injury following extracellular vesicle and focused ultrasound combination therapy. Int J Mol Sci. 2020:21(11)

63. Bruno S, Tapparo M, Collino F, Chiabotto G, Deregibus MC, Lindoso RS, et al. Renal regenerative potential of different extracellular vesicle populations derived from bone marrow mesenchymal stromal cells. Tissue Eng A. 2017; 23(21-22):1262-73. https://doi.org/10.1089/ten.tea.2017.0069.

64. Zhang R, Zhu Y, Li Y, Liu W, Yin L, Yin S, Ji C, Hu Y, Wang Q, Zhou X, Chen J, Xu W, Qian H. Human umbilical cord mesenchymal stem cell exosomes alleviate sepsis-associated acute kidney injury via regulating microRNA-146b expression. Biotechnol Lett. 2020;42(4):669-79. https://doi.org/10.1007/s1052 9-020-02831-2.

65. Gao F, Zuo B, Wang Y, Li S, Yang J, Sun D. Protective function of exosomes from adipose tissue-derived mesenchymal stem cells in acute kidney injury through SIRT1 pathway. Life Sci. 2020;255:117719. https://doi.org/10.1016/j. Ifs.2020.117719.

66. Bassegoda O, Huelin P, Ariza X, Sole C, Juanola A, Gratacos-Gines J, et al. Development of chronic kidney disease after acute kidney injury in patients with cirrhosis is common and impairs clinical outcomes. J Hepatol. 2020; 72(6):1132-9. https://doi.org/10.1016/j.jhep.2019.12.020.

67. See EJ, Jayasinghe K, Glassford N, Bailey M, Johnson DW, Polkinghorne KR, Toussaint ND, Bellomo R. Long-term risk of adverse outcomes after acute kidney injury: a systematic review and meta-analysis of cohort studies using consensus definitions of exposure. Kidney Int. 2019;95(1):160-72. https://doi. org/10.1016/j.kint.2018.08.036. 
68. Yoon YM, Lee JH, Song K-H, Noh H, Lee SH. Melatonin-stimulated exosomes enhance the regenerative potential of chronic kidney disease-derived mesenchymal stem/stromal cells via cellular prion proteins. J Pineal Res. 2020;68(3)

69. Saberi K, Pasbakhsh P, Omidi A, Borhani-Haghighi M, Nekoonam S, Omidi N, Ghasemi S, Kashani IR. Melatonin preconditioning of bone marrow-derived mesenchymal stem cells promotes their engraftment and improves renal regeneration in a rat model of chronic kidney disease. J Mol Histol. 2019; 50(2):129-40. https://doi.org/10.1007/s10735-019-09812-4.

70. Makhlough A, Shekarchian S, Moghadasali R, Einollahi B, Dastgheib M, Janbabaee G, Hosseini SE, Falah N, Abbasi F, Baharvand H, Aghdami N. Bone marrow-mesenchymal stromal cell infusion in patients with chronic kidney disease: a safety study with 18 months of follow-up. Cytotherapy. 2018;20(5):660-9. https://doi.org/10.1016/j.jcyt.2018.02.368.

71. Liu B, Ding F-X, Liu Y, Xiong G, Lin T, He D-W, Zhang YY, Zhang DY, Wei GH. Human umbilical cord-derived mesenchymal stem cells conditioned medium attenuate interstitial fibrosis and stimulate the repair of tubular epithelial cells in an irreversible model of unilateral ureteral obstruction. Nephrology. 2018;23(8):728-36. https://doi.org/10.1111/nep.13099.

72. Ramirez-Bajo MJ, Martin-Ramirez J, Bruno S, Pasquino C, Banon-Maneus E, Rovira J, et al. Nephroprotective potential of mesenchymal stromal cells and their extracellular vesicles in a murine model of chronic cyclosporine nephrotoxicity. Front Cell Dev Biol. 2020;8

73. Kholia S, Herrera Sanchez MB, Cedrino M, Papadimitriou E, Tapparo M, Deregibus MC, et al. Mesenchymal stem cell derived extracellular vesicles ameliorate kidney injury in aristolochic acid nephropathy. Front Cell Dev Biol. 2020;8:188.

74. Wang B, Yao K, Huuskes BM, Shen H-H, Zhuang J, Godson C, Brennan EP, Wilkinson-Berka JL, Wise AF, Ricardo SD. Mesenchymal stem cells deliver exogenous microRNA-let7c via exosomes to attenuate renal fibrosis. Mo Ther. 2016;24(7):1290-301. https://doi.org/10.1038/mt.2016.90.

75. Zhang L, Zhu X-Y, Zhao Y, Eirin A, Liu L, Ferguson CM, et al. Selective intrarenal delivery of mesenchymal stem cell-derived extracellular vesicles attenuates myocardial injury in experimental metabolic renovascular disease. Basic Res Cardiol. 2020;115(2)

76. Chen L, Wang Y, Li S, Zuo B, Zhang X, Wang F, Sun D. Exosomes derived from GDNF-modified human adipose mesenchymal stem cells ameliorate peritubular capillary loss in tubulointerstitial fibrosis by activating the SIRT1/ eNOS signaling pathway. Theranostics. 2020;10(20):9425-42. https://doi. org/10.7150/thno.43315.

77. Zhu F, Shin OLSCL, Pei G, Hu Z, Yang J, Zhu H, et al. Adipose-derived mesenchymal stem cells employed exosomes to attenuate AKI-CKD transition through tubular epithelial cell dependent Sox9 activation. Oncotarget. 2017;8(41):70707-26. https://doi.org/10.18632/oncotarget.1 9979.

78. Packham DK, Fraser IR, Kerr PG, Segal KR. Allogeneic mesenchymal precursor cells (MPC) in diabetic nephropathy: a randomized, placebocontrolled, dose escalation study. Ebiomedicine. 2016;12:263-9. https://doi org/10.1016/j.ebiom.2016.09.011.

79. Nagaishi K, Mizue Y, Chikenji T, Otani M, Nakano M, Saijo Y, Tsuchida H, Ishioka S, Nishikawa A, Saito T, Fujimiya M. Umbilical cord extracts improve diabetic abnormalities in bone marrow-derived mesenchymal stem cells and increase their therapeutic effects on diabetic nephropathy. Sci Rep. 2017;7(1):8484. https://doi.org/10.1038/s41598-017-08921-y.

80. Li Y, Liu J, Liao G, Zhang J, Chen Y, Li L, Li L, Liu F, Chen B, Guo G, Wang C, Yang L, Cheng J, Lu Y. Early intervention with mesenchymal stem cells prevents nephropathy in diabetic rats by ameliorating the inflammatory microenvironment. Int J Mol Med. 2018;41(5):2629-39. https://doi.org/10.3 892/ijmm.2018.3501.

81. Liu Q, Lv S, Liu J, Liu S, Wang Y, Liu G. Mesenchymal stem cells modified with angiotensin-converting enzyme 2 are superior for amelioration of glomerular fibrosis in diabetic nephropathy. Diabetes Res Clin Pract. 2020; 162:108093. https://doi.org/10.1016/j.diabres.2020.108093.

82. Gallo S, Gili M, Lombardo G, Rossetti A, Rosso A, Dentelli P, et al. Stem cellderived, microRNA-carrying extracellular vesicles: a novel approach to interfering with mesangial cell collagen production in a hyperglycaemic setting. PLoS One. 2016;11(9)

83. Duan Y-R, Chen B-P, Chen F, Yang S-X, Zhu C-Y, Ma Y-L, Li Y, Shi J. Exosomal microRNA-16-5p from human urine-derived stem cells ameliorates diabetic nephropathy through protection of podocyte. J Cell Mol Med. 2019; https:// doi.org/10.1111/jcmm.14558.
84. Duan Y, Luo Q, Wang Y, Ma Y, Chen F, Zhu X, Shi J. Adipose mesenchymal stem cell-derived extracellular vesicles containing microRNA-26a-5p target TLR4 and protect against diabetic nephropathy. J Biol Chem. 2020;295(37): 12868-84. https://doi.org/10.1074/jbc.RA120.012522.

85. Zhong L, Liao G, Wang X, Li L, Zhang J, Chen Y, Liu J, Liu S, Wei L, Zhang W, Lu Y. Mesenchymal stem cells-microvesicle-miR-451a ameliorate early diabetic kidney injury by negative regulation of P15 and P19. Exp Biol Med. 2018;243(15-16):1233-42. https://doi.org/10.1177/1535370218819726.

86. Grange C, Tritta S, Tapparo M, Cedrino M, Tetta C, Camussi G, Brizzi MF. Stem cell-derived extracellular vesicles inhibit and revert fibrosis progression in a mouse model of diabetic nephropathy. Sci Rep. 2019;9(1):4468. https:// doi.org/10.1038/s41598-019-41100-9.

87. Jin J, Wang Y, Zhao L, Zou W, Tan M, He Q. Exosomal miRNA-215-5p derived from adipose-derived stem cells attenuates epithelial-mesenchymal transition of podocytes by inhibiting ZEB2. Biomed Res Int. 2020;2020:1-14. https://doi.org/10.1155/2020/2685305

88. Ebrahim N, Ahmed IA, Hussien NI, Dessouky AA, Farid AS, Elshazly AM, et al. Mesenchymal stem cell-derived exosomes ameliorated diabetic nephropathy by autophagy induction through the mTOR signaling pathway. Cells. 2018;7(12)

89. Jin J, Shi Y, Gong J, Zhao L, Li Y, He Q, Huang H. Exosome secreted from adipose-derived stem cells attenuates diabetic nephropathy by promoting autophagy flux and inhibiting apoptosis in podocyte. Stem Cell Res Ther. 2019:10(1):95. https://doi.org/10.1186/s13287-019-1177-1.

90. Eirin A, Zhu X-Y, Ferguson CM, Riester SM, van Wijnen AJ, Lerman A, Lerman LO. Intra-renal delivery of mesenchymal stem cells attenuates myocardial injury after reversal of hypertension in porcine renovascular disease. Stem Cell Res Ther. 2015;6(1):7. https://doi.org/10.1186/scrt541.

91. Saad A, Dietz AB, Herrmann SMS, Hickson LJ, Glockner JF, McKusick MA, et al. Autologous mesenchymal stem cells increase cortical perfusion in renovascular disease. J Am Soc Nephrol. 2017;28(9):2777-85. https://doi. org/10.1681/ASN.2017020151.

92. Abumoawad A, Saad A, Ferguson CM, Eirin A, Herrmann SM, Hickson LJ, et al. In a phase 1a escalating clinical trial, autologous mesenchymal stem cell infusion for renovascular disease increases blood flow and the glomerular filtration rate while reducing inflammatory biomarkers and blood pressure. Kidney Int. 2020;97(4):793-804. https://doi.org/10.1016/j. kint.2019.11.022.

93. Sivanathan KN, Coates PT. Improving human kidney function in renovascular disease with mesenchymal stem cell therapy. Kidney Int. 2020; 97(4):655-6. https://doi.org/10.1016/j.kint.2019.12.020.

94. Eirin A, Zhu X-Y, Jonnada S, Lerman A, van Wijnen AJ, Lerman LO. Mesenchymal stem cell-derived extracellular vesicles improve the renal microvasculature in metabolic renovascular disease in swine. Cell Transplant 2018;27(7):1080-95. https://doi.org/10.1177/0963689718780942.

95. Simeoni M, Borrelli S, Garofalo C, Fuiano G, Esposito C, Comi A, et al. Atherosclerotic-nephropathy: an updated narrative review. J Nephrol. 2021; 34(1):125-36.

96. Song $T$, Eirin $A$, Zhu $X$, Zhao $Y$, Krier JD, Tang $H$, Jordan $K L$, Woollard JR, Taner T, Lerman A, Lerman LO. Mesenchymal stem cell-derived extracellular vesicles induce regulatory $T$ cells to ameliorate chronic kidney injury. Hypertension. 2020;75(5):1223-32. https://doi.org/10.1161/HYPERTENSIONA HA.119.14546.

97. Eirin A, Zhu X-Y, Puranik AS, Tang H, McGurren KA, van Wijnen AJ, et al. Mesenchymal stem cell-derived extracellular vesicles attenuate kidney inflammation. Kidney Int. 2017;92(1):114-24. https://doi.org/10.1016/j.kint.201 6.12.023.

98. Kim SR, Zou X, Tang H, Puranik AS, Abumoawad AM, Zhu X-Y, et al. Increased cellular senescence in the murine and human stenotic kidney: effect of mesenchymal stem cells. J Cell Physiol. 2021;236(2): 1332-44.

99. Eirin A, Ferguson CM, Zhu X-Y, Saadiq IM, Tang H, Lerman A, Lerman LO. Extracellular vesicles released by adipose tissue-derived mesenchymal stromal/stem cells from obese pigs fail to repair the injured kidney. Stem Cell Res. 2020;47:101877. https://doi.org/10.1016/j.scr.2020.101877.

100. Pawar AS, Eirin A, Tang H, Zhu X-Y, Lerman A, Lerman LO. Upregulated tumor necrosis factor-alpha transcriptome and proteome in adipose tissuederived mesenchymal stem cells from pigs with metabolic syndrome. Cytokine. 2020;130:155080. https://doi.org/10.1016/j.cyto.2020.155080.

101. Li Y, Meng Y, Zhu X, Saadiq IM, Jordan KL, Eirin A, et al. Metabolic syndrome increases senescence-associated micro-RNAs in extracellular vesicles derived 
from swine and human mesenchymal stem/stromal cells. Cell Commun Signal. 2020;18(1)

102. Zhao Y, Zhu X, Zhang L, Ferguson CM, Song T, Jiang K, Conley SM, Krier JD, Tang H, Saadiq I, Jordan KL, Lerman A, Lerman LO. Mesenchymal stem/ stromal cells and their extracellular vesicle progeny decrease injury in poststenotic swine kidney through different mechanisms. Stem Cells Dev. 2020;29(18):1190-200. https://doi.org/10.1089/scd.2020.0030.

103. Jain S, Plenter R, Nydam T, Jani A. Injury pathways that lead to AKI in a mouse kidney transplant model. Transplantation. 2020;104(9):1832-41. https://doi.org/10.1097/TP.0000000000003127.

104. Wekerle T, Segev D, Lechler R, Oberbauer R. Strategies for long-term preservation of kidney graft function. Lancet. 2017;389(10084):2152-62. https://doi.org/10.1016/50140-6736(17)31283-7.

105. del Rio F, Andres A, Padilla M, Sanchez-Fructuoso Al, Molina M, Ruiz A, et al. Kidney transplantation from donors after uncontrolled circulatory death: the Spanish experience. Kidney Int. 2019;95(2):420-8. https://doi.org/10.1016/j. kint.2018.09.014

106. Tan J, Wu W, Xu X, Liao L, Zheng F, Messinger S, Sun X, Chen J, Yang S, Cai J, Gao X, Pileggi A, Ricordi C. Induction therapy with autologous mesenchymal stem cells in living-related kidney transplants a randomized controlled trial. JAMA. 2012;307(11):1169-77. https://doi.org/10.1001/jama.2 012.316 .

107. Sun Q, Huang Z, Han F, Zhao M, Cao R, Zhao D, Hong L, Na N, Li H, Miao B, Hu J, Meng F, Peng Y, Sun Q. Allogeneic mesenchymal stem cells as induction therapy are safe and feasible in renal allografts: pilot results of a multicenter randomized controlled trial. J Transl Med. 2018;16(1):52. https:// doi.org/10.1186/s12967-018-1422-x.

108. Gregorini M, Corradetti V, Pattonieri EF, Rocca C, Milanesi S, Peloso A, Canevari S, de Cecco L, Dugo M, Avanzini MA, Mantelli M, Maestri M, Esposito P, Bruno S, Libetta C, Dal Canton A, Rampino T. Perfusion of isolated rat kidney with mesenchymal stromal cells/extracellular vesicles prevents ischaemic injury. J Cell Mol Med. 2017;21(12):3381-93. https://doi org/10.1111/jcmm.13249.

109. Koch M, Lemke A, Lange C. Extracellular vesicles from MSC modulate the immune response to renal allografts in a MHC disparate rat model. Stem Cells Int. 2015;2015:1-7. https://doi.org/10.1155/2015/486141.

110. Jose Ramirez-Bajo M, Rovira J, Lazo-Rodriguez M, Banon-Maneus E, Tubita V, Moya-Rull D, et al. Impact of mesenchymal stromal cells and their extracellular vesicles in a rat model of kidney rejection. Front Cell Dev Biol. 2020;8

111. Iseri K, lyoda M, Ohtaki H, Matsumoto K, Wada Y, Suzuki T, Yamamoto $Y$, Saito T, Hihara K, Tachibana S, Honda K, Shibata T. Therapeutic effects and mechanism of conditioned media from human mesenchymal stem cells on anti-GBM glomerulonephritis in WKY rats. Am J Physioly Renal Physiol. 2016; 310(11):F1182-F91. https://doi.org/10.1152/ajprenal.00165.2016.

112. Cheng R-J, Xiong A-J, Li Y-H, Pan S-Y, Zhang Q-P, Zhao Y, Liu Y, Marion TN. Mesenchymal stem cells: allogeneic MSC may be immunosuppressive but autologous MSC are dysfunctional in lupus patients. Front Cell Dev Biol. 2019;7 https://doi.org/10.3389/fcell.2019.00285.

113. Barbado J, Tabera S, Sanchez A, Garcia-Sancho J. Therapeutic potential of allogeneic mesenchymal stromal cells transplantation for lupus nephritis. Lupus. 2018;27(13):2161-5. https://doi.org/10.1177/0961203318804922.

114. Kim HS, Lee JS, Lee HK, Park EJ, Jeon HW, Kang YJ, et al. Mesenchymal stem cells ameliorate renal inflammation in adriamycin-induced nephropathy. Immune Netw. 2019;19(5)

115. Starc N, Li M, Algeri M, Conforti A, Tomao L, Pitisci A, Emma F, Montini G, Messa P, Locatelli F, Bernardo ME, Vivarelli M. Phenotypic and functional characterization of mesenchymal stromal cells isolated from pediatric patients with severe idiopathic nephrotic syndrome. Cytotherapy. 2018; 20(3):322-34. https://doi.org/10.1016/j.jcyt.2017.12.001.

116. Hyun YY, Kim IO, Kim MH, Nam DH, Lee MH, Kim JE, Song HK, Cha JJ, Kang YS, Lee JE, Kim HW, Han JY, Cha DR. Adipose-derived stem cells improve renal function in a mouse model of IgA nephropathy. Cell Transplant. 2012; 21(11):2425-39. https://doi.org/10.3727/096368912X639008.

117. Chang H-H, Hsu S-P, Chien C-T. Intrarenal transplantation of hypoxic preconditioned mesenchymal stem cells improves glomerulonephritis through anti-oxidation, anti-ER stress, anti-inflammation, anti-apoptosis, and antiAutophagy. Antioxidants. 2020;9(1)

118. Varela VA, Oliveira-Sales EB, Maquigussa E, Borges FT, Gattai PP, Novaes ADS, et al. Treatment with mesenchymal stem cells improves renovascular hypertension and preserves the ability of the contralateral kidney to excrete sodium. Kidney Blood Press Res. 2019;44(6):1404-15. https://doi.org/10.1159/ 000503346.

119. Gregorini M, Maccario R, Avanzini MA, Corradetti V, Moretta A, Libetta C, Esposito P, Bosio F, Dal Canton A, Rampino T. Antineutrophil cytoplasmic antibody-associated renal vasculitis treated with autologous mesenchymal stromal cells: evaluation of the contribution of immune-mediated mechanisms. Mayo Clin Proc. 2013;88(10):1174-9. https://doi.org/10.1016/j. mayocp.2013.06.021.

120. Makhlough A, Shekarchian S, Moghadasali R, Einollahi B, Hosseini SE, Jaroughi N, Bolurieh T, Baharvand H, Aghdami N. Safety and tolerability of autologous bone marrow mesenchymal stromal cells in ADPKD patients. Stem Cell Res Ther. 2017;8(1):116. https://doi.org/10.1186/s13287-017-0557-7.

121. Shi Y, Xie J, Yang M, Ma J, Ren H. Transplantation of umbilical cord mesenchymal stem cells into mice with focal segmental glomerulosclerosis delayed disease manifestation. Ann Transl Med. 2019;7(16)

\section{Publisher's Note}

Springer Nature remains neutral with regard to jurisdictional claims in published maps and institutional affiliations. 